\section{Reseña / La comunicación en los territorios. Experiencias en la construcción colectiva del conocimiento}

González, N. D. y Alfonso, A. (Comps) (2019). La comunicación en los territorios. Experiencias en la construcción colectiva del conocimiento, Universidad Nacional Quilmes. Serie experiencias. Publicaciones Ciencias Sociales. ISBN 978-987-558-588-1 Sitio de descarga gratuita: http://unidaddepublicaciones.web. unq.edu.ar/libros/la-comunicacion-en-los-territoriosexperiencias-en-la-construccion-colectiva-del-conocimiento/

\author{
Por Luis Héctor Amaranto Barreras \\ Universidad Nacional de Avellaneda, Buenos Aires, Argentina. \\ Ibarreras@undav.edu.ar \\ (iD orcid.org/0000-0002-0513-4820
}

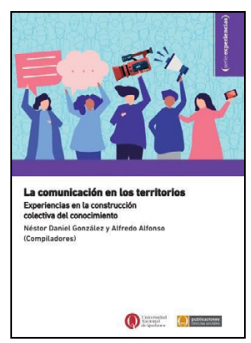

Hablar de comunicación y extensión universitaria nos permite pensar en Paulo Freire (1971), quien se preguntaba acerca de ¿extensión o comunicación?, y en esa línea señalaba que: "La educación es comunicación, es diálogo, en la medida en que no es la transferencia del saber, sino un encuentro de sujetos interlocutores, que buscan la significación de los significados" (p. 77). "El diálogo es el encuentro amoroso de los hombres que, mediatizados por el mundo, lo pronuncian, esto es, lo transforman y, transformándolo, lo humanizan, para la humanización de todos" (p. 46).

El libro La comunicación en los territorios nos sumerge en diálogos de saberes horizontales, mancomunados entre los saberes populares y académicos, en relatos sobre una realidad contada con y desde los territorios, que cuentan con actores sociales, organizaciones.

En ese sentido, este texto plasma la idea de que el Compromiso Social Universitario, la extensión universitaria, implica entender desde una perspectiva ético-política a la Educación Superior como un bien público, social, un derecho humano, universal, y un deber del Estado para con el pueblo. Este compromiso se manifiesta en el acceso a la educación, en las pedagogías implementadas, en la co-construcción de conocimiento con los saberes populares, con los colectivos sociales, con el acceso a saberes alternativos que promuevan conocimientos decoloniales, antipatriarcales, anticapitalistas, en favor de una universidad más empática.

Los compiladores y autores del libro realizan un recorrido sobre la extensión universitaria, sus alcances, su historia, en diálogo con el campo disciplinar de la comunicación, las diversas acepciones y formas que adquiere, como el desarrollo cultural, la transferencia científica y tecnológica, la comunicación de la ciencia, la realización de servicios, y toda actividad tendiente a consolidar la relación entre la universidad y la sociedad.

Asimismo, se analizan los diversos modelos que aparecen en la extensión universitaria, como: extensionismo/transferencia; la comunicación como herramienta de inclusión y transformación; la extensión como articulación académica; la comunicación como herramienta de inclusión y transformación.

Uno de los puntos de inflexión del aporte realizado por los autores es pensar la comunicación como un proceso, más allá de los medios masivos, entendiendo la importancia de concebirla no como difusión sino como democratizadora de la palabra, de la puesta en diá- 
logo. En ese punto, se hace un detallado análisis crítico de la importancia de las carreras de comunicación, las prácticas que desarrollan y el rol de los y las estudiantes en la promoción de la formación de profesionales no a los fines del mercado sino, como dijo Rodolfo Walsh, en cuanto a que la universidad no solo debe formar en la perspectiva de un pensamiento crítico sino respecto de sentir como propio el dolor ajeno.

Nancy Díaz Llarrañaga y Paz Echeverría nos permiten repensar la idea de territorio lejos de concebirlo solamente como "localización geográfica, es decir, como una extensión de tierra/agua/aire con límites trazados artificialmente — por lo general, cercanos al ámbito universitario- que suelen estar demarcados y ser reconocidos por la comunidad. Aquí podemos leer presentaciones sobre cómo la universidad tiene que "extenderse", "ocupar más territorio", "vincularse con sus cercanías", entre otros temas.

Las autoras nos plantean pensar el territorio "como eso que realizamos con otras personas; las prácticas y los haceres que nos permiten encontrarnos. Esto podría referirse a que lo considerado común no se da por el espacio compartido sino por el trabajo conjunto". Proponen la noción de que no trabajamos en territorios sino que aportamos a la construcción colectiva de esos territorios que somos.

Daniel Badenes nos trae un abordaje desde los medios alternativos, populares, alejados de la idea de la industria cultural que confunde lo popular con lo masivo, con el consumo. En este apartado se advierte la importancia de generar procesos alternativos populares de comunicación que estén al servicio de las expresiones y necesidades de los pueblos y que su desarrollo sea autogestivo.

Otra de las experiencias que narra este libro es la disputa de sentido que se construyó en el artículo de "Comunicación, medios y lenguajes mediáticos". En el mismo se relata la propuesta de "Cronistas Barriales", una experiencia audiovisual estético-política que construye un lenguaje identitario de las noticias locales, alejadas de la representación mediática de los medios masivos de comunicación.

En suma, el libro aborda la idea de sistematización de experiencias que implica, en palabras de Oscar Jara (2020): "La interpretación crítica y rescate de aprendizajes de procesos históricos, vitales, complejos, en los que intervienen diferentes actores" (p. 62). La comunicación en los territorios es un minucioso relato de historias, aprendizajes, experiencias que nos humanizan y sensibilizan.

Pepe Mujica, en su renuncia al Senado uruguayo, decía: "Triunfar en la vida no es ganar, triunfar en la vida es levantarse y volver a empezar cada vez que uno cae". Creo que este libro implica dos cosas que son centrales: un acto político (la posibilidad de transformación) y un acto de amor (la posibilidad de crear) en los términos que Pepe lo señalaba. Aquí encontramos las herramientas y el conocimiento en diálogo de saberes que permiten a los sectores más vulnerables levantarse y volver a empezar. Pasen y lean.

\section{Referencias bibliográficas}

Freire, P. (1971). ¿Extensión o comunicación?, La concientización en el medio rural. Tierra Nueva. Jara, O. (2020). La educación popular latinoamericana. Historia y claves éticas, políticas y pedagógicas. Universidad Nacional de Jujuy. 